
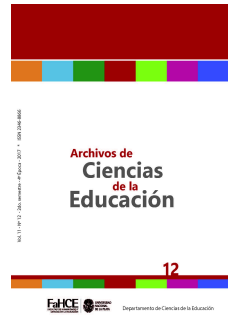

Archivos de Ciencias de la Educación, Vol 11, nº 12, diciembre 2017, e036. ISSN 2346-8866 Universidad Nacional de La Plata.

Facultad de Humanidades y Ciencias de la Educación.

Departamento de Ciencias de la Educación.

\title{
Alliaud, A. (2017). Los artesanos de la enseñanza. Acerca de la formación de maestros con oficio. Buenos Aires: Paidós
}

\section{Silvana Ollier}

Universidad Nacional de La Plata, Argentina | silollier@yahoo.com

\begin{abstract}
Andrea Alliaud es Doctora en Ciencias de la Educación por la Universidad de Buenos Aires. Docente e investigadora del Departamento de Ciencias de la Educación de la Facultad de Filosofía y Letras (UBA). Es profesora de posgrado en la Carrera de Especialización y Maestría en Administración de la Educación y Política de la Universidad Torcuato Di Tella. Su área de especialización, desde hace más de veinticinco años, es la formación de profesores; temática sobre la que investigó, disertó y publicó tanto en la Argentina como en el exterior.

Desde las primeras páginas de su libro "Los artesanos de la enseñanza. Acerca de la formación de maestros con oficio”, Alliaud propone un recorrido que invita al lector a preguntarse: ¿Podemos pensar la docencia como una práctica artesanal? ¿Observar los trabajos y los modos en que se transmiten los saberes, puede ser una fuente de inspiración para formar en la enseñanza? ¿Dada su especificidad, puede la docencia analogarse a otros trabajos?

En la introducción la autora presenta su obra como pedagógica y artesanal, fruto de un largo trabajo de indagación y reflexión sobre cuestiones del sistema educativo especialmente vinculadas a la formación docente. Nombres de pedagogos, sociólogos y filósofos como Philip Jackson, Philippe Meirieu, François Dubet, Daniel Pennac y George Steiner son presentados como sus principales referentes, mereciendo una alusión especial la voz de Richard Sennett desde su obra "El artesano" (2009).
\end{abstract}


Las páginas que siguen se despliegan sobre cuatro pilares (manera particular de nombrar cada capítulo) que pueden leerse -según la invitación de la autora- en el orden en que son presentados o invirtiendo el recorrido. El libro promueve la producción de la propia enseñanza y de las propias prácticas de formación, permitiendo al lector enriquecer el contenido desde sus experiencias. Es por esta razón que Alliaud plantea que su obra está inconclusa.

En el primer pilar, Sobre las Instituciones: las escuelas ya no son lo que eran, la autora recupera reflexiones de Dubet (2006) sobre el declive de las instituciones en la actualidad, tiempos en los que el programa institucional de la modernidad se ha resquebrajado. La escuela se presenta en estas páginas como la institución que permite el pasaje de la cultura de una generación a otra de manera sistemática, siendo su esencia la educación, la enseñanza y la transmisión. Al cerrar este apartado la autora manifiesta que "enseñar... sigue implicando intervenir con otro y sobre otro en un sentido formador, transformador, emancipador. La liberación de los sujetos es su consecuencia, no el punto de partida...” (p. 32).

Desde el segundo pilar llamado Sobre la enseñanza; recuperar la perspectiva de oficio, Alliaud acerca definiciones de la enseñanza como artesanía, entendida como la habilidad de hacer algo bien por el simple hecho de hacerlo de ese modo (Sennett, 2009). La autora enfatiza que la enseñanza siempre se da con otros y sobre otros, y hacerlo bien constituye una de las mejores recompensas para quienes tienen este oficio. A su vez, retomando a Meirieu (2006), plantea que el acto pedagógico siempre encierra algo del orden de lo inesperado, no puede estar programado por nadie ya que a pesar de hacer todo para que se produzca no es posible desencadenarlo mecánicamente. Antes de referirnos al tercer pilar, se retoman las siguientes palabras de la autora referidas al acto de enseñar:

Son precisamente esos secretos de fabricación, ese algo, lo que está en juego en lo más íntimo del acto de enseñar. Una especie de vibración particular de la que son portadores los docentes y que no se puede reducir a una lista de competencias. Esos secretos van tomando forma práctica, a medida que se van enseñando, y parecen ser productos de una rara fórmula de métodos, técnicas, modos de actuar que en principio permiten distinguir lo que funciona bien de lo que no (p. 41).

El tercer pilar se titula La formación docente: sus temas y desafíos y hace referencia a la formación de los maestros y a la relación entre la teoría y práctica. Alliaud reconoce la centralidad que la formación docente ocupa en debates y propuestas de mejora del sistema educativo, así como la problemática relación entre la teoría y la práctica, entre el decir y el hacer, entre el pensamiento y la acción. Señala la necesidad de recuperar en la formación docente espacios para la transmisión de saberes de oficio que incluyen procedimientos, habilidades y estrategias de enseñanza. Como expresa la autora: "Enseñar hoy es aprender a permanecer en la confusión, en la imprevisibilidad, es poder pensar y decidir en contextos de cambio" (p. 73). Se aleja así de todo tipo de aplicacionismo directo en el aula de lo aprendido en el profesorado.

Alliaud sostiene que lo propio de los saberes de la experiencia se encuentra en la posibilidad de entramar los conocimientos con la práctica, el saber con el hacer. Se trata de saberes que se producen en situación pero que no son fácilmente verbalizables. En palabras de Terigi (2012), muchas veces se producen y actualizan sin que los docentes sean conscientes de ello. Según Alliaud, son estos saberes de la experiencia los que deben ser puestos en valor y circular no solo en los ámbitos de formación docente sino también en los de producción de conocimiento pedagógico. Así lo expresa:

...las instancias de formación inicial y continua tendrían que posibilitar que los saberes que se producen al enseñar sean tratados y capitalizados como saberes de la experiencia, lo cual implica procedimientos reflexivos que no se garantizan mediante un posicionamiento disociado de lo que sucede, sino que suponen una inmersión distinta en la realidad, como es la de estar 
abiertos a lo que acontece y seguir aprendiendo a partir de lo que las situaciones tienen para enseñarnos (p. 6).

El oficio de enseñar se construye a lo largo de todo el proceso formativo. Durante este recorrido resulta fundamental dar lugar al saber que se produce al enseñar, creando y recreando formas que superen la dicotomía entre la teoría y la práctica. Entre las formas de recuperar el saber de la experiencia, Alliaud propone convocar a docentes narradores para hablar sobre su trabajo. Estos relatos de experiencias pedagógicas, en los que se incluyen no sólo procedimientos sino también secretos y trucos del oficio, podrían a su vez plasmarse por escrito. Según Alliaud y Antelo (2008) es preciso probar, practicar, discutir y analizar distintas maneras de dar a conocer el mundo y de poner a disposición de los otros aquello que tienen que aprender. Los maestros y profesores en formación no solo tienen que aprender sobre la enseñanza sino a enseñar. Alliaud afirma que son los saberes de experiencia los que nutren la enseñanza, de allí la necesidad de asegurar su presencia en el trayecto formativo de los futuros docentes, llegando así a ser artesanos en el arte de enseñar. Sumando los aportes de Sennett (2009), la autora plantea que el aprendizaje del oficio requiere situaciones específicas de formación que suponen el encuentro entre novatos y experimentados. Espacios en los que mostrar, hacer, acompañar, experimentar, probar y explicitar lo que se hace posibilitan la transmisión de ese oficio.

El cuarto pilar se titula Hacia la formación de los artesanos de la enseñanza, y consta de dos partes. En la primera, se plantea que la artesanía mejora al ser practicada como un oficio cualificado. La autora recupera a la práctica como espacio privilegiado para transmitir el oficio de enseñar e invita a pensar qué y cómo se transmite. Al responder señala que se transmiten capacidades, compromiso y confianza desde la repetición, la imaginación y la colaboración. Si los formadores son los responsables de transmitir el oficio a quienes se están formando, se requiere crear las condiciones y los dispositivos para que esto acontezca. La autora pone en valor la inclusión de diversos dispositivos durante el proceso formativo que posibiliten la articulación entre la dimensión práctica del oficio y las teorías desde las que se sostiene esa práctica. Entre otros, estos dispositivos incluyen: relatos, narraciones, biografías, películas, observaciones y planificaciones. Se propone un abordaje desde formas de trabajo colaborativo que propicien el análisis y la reflexión. Aquí ocupa un lugar destacado el profesor de práctica. El docente en formación aprende a enseñar desde las enseñanzas que ese maestro imparte, esto puede ser sintetizado en las palabras de Meirieu (2001), dime cómo te enseñaron y te diré cómo enseñas. Alliaud sostiene que la formación y el acompañamiento durante los primeros años de desempeño profesional deberían incluir experiencias del saber hacer, saber sentir y saber estar, fomentando la comunicación y alentando el intercambio.

En la segunda parte se presentan técnicas con implicaciones expresivas: aprender de la propia experiencia y de la experiencia de otros, poner en palabras lo que se hizo y lo acontecido en la clase. Este tipo de trabajo enriquece el proceso de aprendizaje de los futuros docentes, aquello que puede resultar obvio para los maestros de artesanos se constituyen en conocimientos valiosos para quienes se están formando. A su vez, la autora propone apelar a figuras propias de otros campos, por ejemplo, imágenes e historias tomadas de la literatura o del cine que permitan acceder a otros mundos enriqueciendo el abanico de posibilidades.

Siguiendo a Sennett (2009), Alliaud plantea que el pasaje de saberes de maestro a aprendiz cobra sentido siempre que quien forma sea capaz de ponerse en el lugar del que aprende. El docente en formación necesita anticipaciones, orientaciones y consejos antes de enfrentar situaciones reales de enseñanza. Será relevante entonces propiciar la circulación y la producción de relatos de experiencias pedagógicas.

La autora ofrece algunos títulos, a los que llama grandes obras de enseñanza, que pueden ayudar a otros a aprender a enseñar. Por ejemplo, la experiencia de Joseph Jacotot -protagonista del libro "El Maestro Ignorante” de Jacques Rancière-, en la que sus alumnos lograron aprender a pesar de desconocer lo que enseñaba, dio lugar a una interesante reflexión acerca del lugar del saber y de la ignorancia al enseñar y 
aprender. O bien, la obra "El Profesor" de Frank McCourt, donde se narran los desafíos que ese profesor enfrentó durante sus treinta años como docente, especialmente al dar los primeros pasos en el aprendizaje del oficio. Alliaud hace algo similar al presentar "El elogio de la transmisión” de George Steiner y Cecile Ladjsli, “Pedagogía Escolar” de Georg Simmel y “La escuela de Yasnaia Polaina” de León Tolstoi.

La obra finaliza con el apartado titulado A Modo de cierre y apertura: la obra continúa y está por realizarse. Allí avanza en precisar los saberes que deberían asegurarse en los ámbitos de la preparación profesional de maestros y profesores. Señala que como no es posible pensar, sentir, experimentar en el vacío, ni dar lugar a la creatividad como motor de nuevos conocimientos, se hace necesario que el conocimiento formalizado permita interrogar, enriquecer e imaginar de otras maneras posibles las situaciones de enseñanza. De este modo, será posible construir el oficio de enseñar a lo largo de toda la formación sin disociar el saber del hacer. Para la autora, el trabajo de enseñar se va construyendo artesanalmente en el día a día. Creando las condiciones propicias es posible que todo/as logren ser artesanos en lo que hacen, en este caso, artesano de la enseñanza.

La relevancia de los aportes de Alliaud para los formadores de formadores y los que inician o transitan su propio trayecto formativo como maestros o profesores, entendiendo o descubriendo lo que implica el oficio de ser artesanos de la enseñanza, es indiscutible. Su obra convoca a reflexionar sobre distintas dimensiones, entre ellas, la importancia del sistema formador de docentes y del sistema escolar en la producción y circulación de relatos de experiencias pedagógicas para que, desde ese encuentro e intercambio, se produzcan nuevos relatos propios de los docentes.

La obra de Alliaud invita, a quienes de alguna manera están comprometidos con la formación de formadores, a considerar su oficio como una artesanía; y de allí, a generar cada vez más espacios para que los aprendices del oficio puedan hacer cada día mejor lo que hacen: aprender a enseñar.

\section{Bibliografía}

Alliaud, A. y Antelo, E. (2008). El fracaso de enseñar. Ideas para pensar la enseñanza y la formación de los futuros docentes, en D. Brailovsky (coord.). Sentidos perdidos de la experiencia escolar. Buenos Aires: Noveduc.

Dubet, F. (2006). El declive de la institución. Profesiones, sujetos e individuos en la modernidad. Barcelona: Gedisa.

Meirieu, PH. (2001). Frankestein educador. Barcelona: Laertes.

Meirieu, PH. (2006). Carta a un joven profesor. Por qué enseñar hoy. Barcelona: Grao.

Sennett, R. (2009). El artesano. Barcelona: Anagrama.

Terigi, F. (2012). Los saberes docentes. Formación, elaboración en la experiencia e investigación, documento básico del VIII Foro de Educación. Buenos Aires: Fundación Santillana. 